\title{
A RARE CONGENITAL ANOMALY OF NOSE - ACCESSORY NOSE : CASE REPORT
}

\author{
N. Radha Krishna,* Benjamin Rajendra Kumar,** K. Srinivas, ${ }^{* *}$ Lenin Akurati.***
}

Abstract: We describe a 21 year old man who was found to have an opening on his extemal nose since birth. No other clinical and radiological abnormalities were demonstrable elsewhere in his body. The opening is on the lower part of the nose one cm. away from the midline on right side, clinically looking like a sinus. Histological examination of the excised tract showed an organoid structure that was. consistent with on "Accessory nose."

Key words: accessory nose, congenital anomaly nose, supernumerary nostril.

\section{INTRODUCTION}

Accessory nose, also known as supernumery nostril, is characterized by the congenital presence of accessory nostril usually close to the midline.The nostril appears similar to the natural ones with vibrissae. It may or may not communicate with the cavity of the nose. It is usually associated with other congenital malformations like submucus cleft palate, incomplete or complete cleft palate or cleft lip, Proboscis lateralis etc. It is believed to be a rare congenital anomaly, occurring during the development of nose in $3^{\text {rd }}$ or $4^{\text {th }}$ week of embryonic period. Adequate knowledge and description of the etiology, pathogenesis and management is lacking in the world literature due to the rarity of the anomaly.

\section{CASE REPORT:}

A 21 year old male presented to the out patient department of our institute with the complaint of presence of an opening on his nose situated $1 \mathrm{~cm}$. lateral to the midline in the lower half of the nose on right side associated with the history of recurrent mucopurulent discharge from the opening(Fig.1) .There is no history of bleeding or continuous watery discharge from the opening. Patient's birth history revealed that he was delivered by full term normal vaginal delivery at home. There was no history of consanguity. No significant finding is present in the maternal history. There is no similar or significant illness or congenital anomalies in the family. He is a non-smoker and non alcoholic.

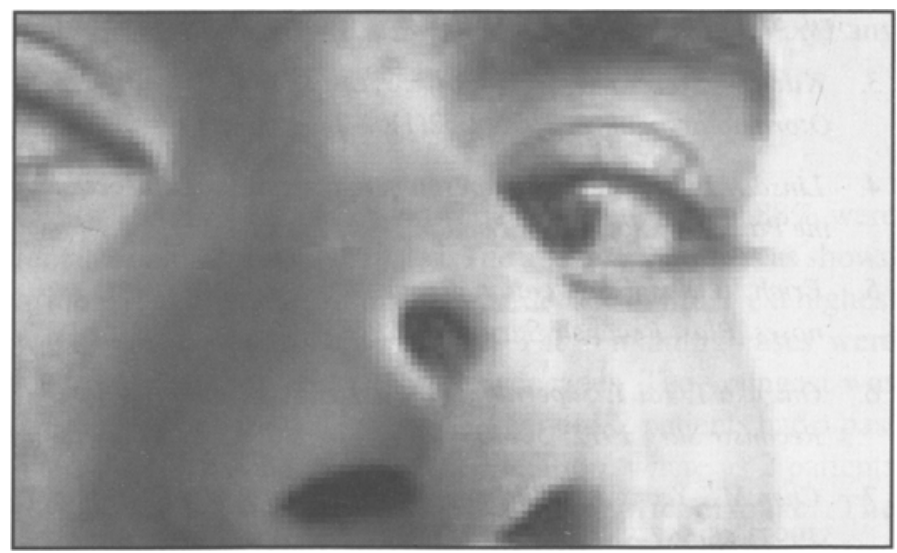

Fig.1: Patient with the accessory nose
He has no other significant illness and is fruit vendor by profession. On examination the opening was present on the lower half the nose, approximately $1 \mathrm{~cm}$. away from the midline. No active bleeding or discharge was noted. There was no other mass or swelling on the nose or anywhere else in the body. Prominent viable hairs noticed near the sinus opening. Skin around the opening is normal. On palpation there was no tenderness. No mass was palpable. Anterior rhinoscopy and posterior rhinoscopy revealed no abnormality. Transillumination through the sinus opening did not reveal continuity of the sinus into the nasal cavity. On probing with Jobson Horne probe the sinus tract was found to end blindly $2 \mathrm{~cm}$ superiorly from the opening.

Diagnostic nasal endoscopy was done which revealed no abnormality. The scope could not be passed in the sinus opening due to smaller size of the opening. Sinogram was performed to know the extent of the tract, which showed the tract ending blindly in the soft tissues of the nose, without any communication to the intracranial structures (Fig.3).

Surgery was undertaken to excise the tract and correct the anomaly (Fig.2), after explaining the patient, the course, prognosis and complications. A circular incision was given around the opening and tract dissected out and sent for histopathological examination, which revealed well formed organoid structure consistent with accessory nose.

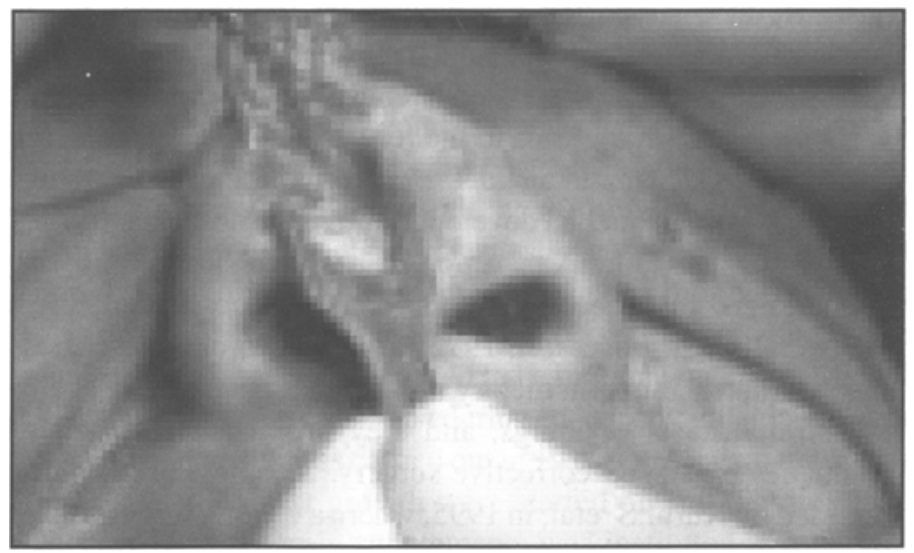

Fig.2: Intraoperative picture of the tract 


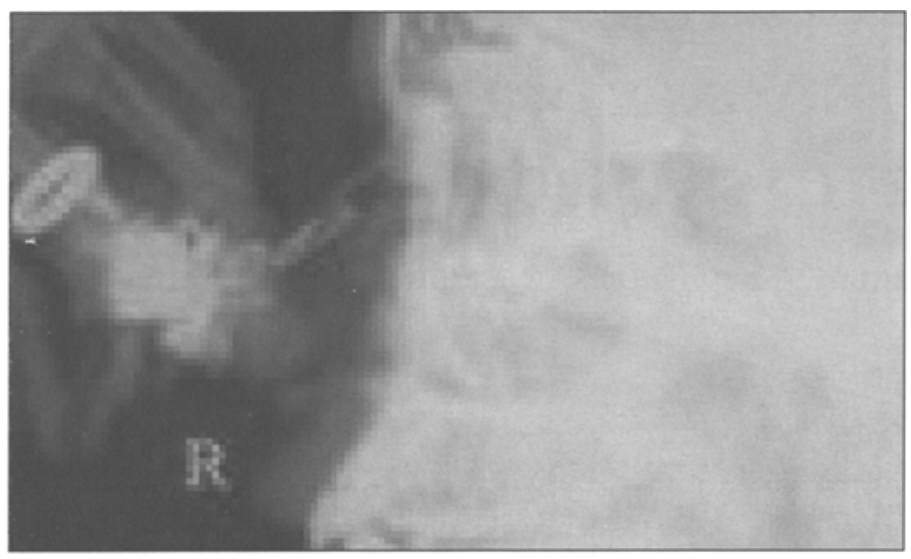

Fig.3: Sinogram showing the extent of the tract

\section{DISCUSSION}

Embryologically, by week 4 of intrauterine life, precursors of nasal cavities and the lenses of the eyes are formed. The nasal placodes (olfactory placodes) arise from the medial aspect of the lower portion of the frontal prominence, and the lens placodes arise from the lateral aspect of the lower portion of the frontal prominence. At week 5, the mesenchyme, which covers the caudal surface of the forebrain, proliferates with the surface ectoderm to form the frontonasal process. Two ectodermal thickenings (the nasal placodes) arise on each side of the dependent part of the frontonasal process. Subsequently, a depression develops in the surrounding mesenchyme on each side of the two nasal placodes, thereby forming two olfactory pits or gutters. These olfactory pits separate the frontonasal process into a medial nasal process and two lateral nasal processes. The lateral nasal processes subsequently form the alae of the nose. As the olfactory pits progress deeper to form the primitive nasal cavity, the medial nasal process thins out gradually to form the primitive nasal septum. At this stage, the maxillary process develops from the cephalic side of the dorsal part of the mandibular arch. Each maxillary process grows ventromedially to meet and fuse with the lateral nasal processes, and each ultimately fuses with the medial nasal process, thus forming the external opening of the primitive nasal cavity and the upper lip.

Supernumerary nostrils are exceedingly rare congenital anomalies of unclear etiology. In 1962, Erich ${ }^{5}$ reported a case of double nose. He also supported Linsday's ${ }^{4}$ theory of dichotomy by atavism or parallel evolution, and he further speculated that if the accessory nasal pit is located too laterally, the fusion of the lamina is not affected, which leads to the formation of a supernumerary nostril. In 1972, Onizuka and Tai ${ }^{6}$ reported the case of a single accessory nostril that had developed above the nasal ala. In 1987, Nakamura and Onizuka ${ }^{9}$ reported a similar case, and they hypothesized that the cause was probably a localized defect in the lateral nasal process. In 1992, Chen and Yeong ${ }^{7}$ described a case of bilateral supernumerary nostrils that were situated below the normal nasal openings, and they proposed treating such anomalies by staged corrective surgery. Another case has been reported by Kurul.S ${ }^{3}$ etal, in 1995, where a 6 year old Turkish girl presented with accessory nose and incomplete cleft palate in 2001, Hallak et al ${ }^{8}$ reported a case of supernumerary nostril in which a

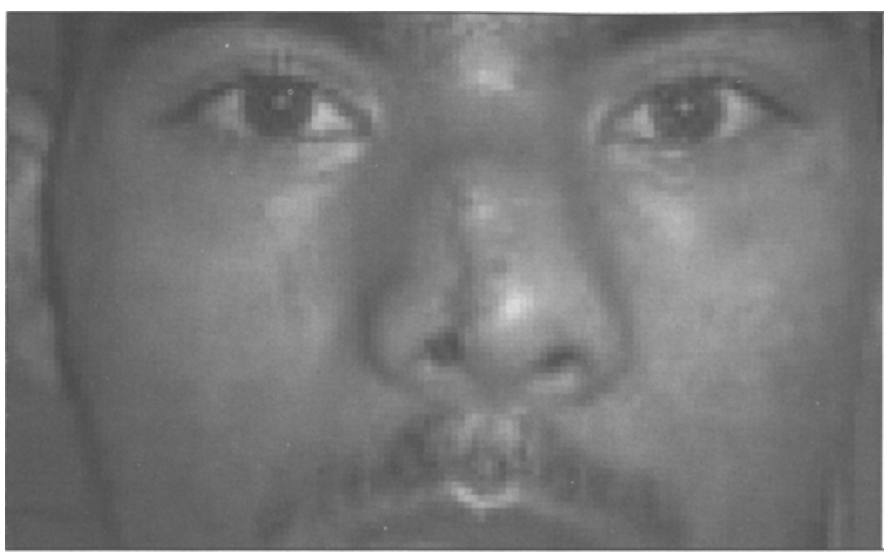

Fig.4: Post operative picture

blind cavity was present in a normally developed nose. They advocated that corrective surgery be performed at an early age to prevent any possible alar deformity. Recently, in 2004, G.Cuervo De Lacalle etal ${ }^{10}$ reported a case of supernumery nostril with ear deformity.

Most reported cases of supernumerary nostrils have been unilateral, and most were associated with other craniofacial malformations, such as a facial cleft ${ }^{10}$. A supernumerary nostril may or may not communicate with the ipsilateral normal nasal cavity, depending on the extent of the anomaly's embryologic progression. Dermoid cyst with sinus can be considered in the differential diagnosis of the accessory nose, but dermoid is usually in the midline, and presents as mass on the nose with small punctum containing hair follicle, and it communicates with intracranial structures. Other midline congenital masses like encephalocele, meningocele, meningomyelocele are not relevant to the case reported here.

To best of our knowledge, this is the first case report of isolated anomaly of accessory nostril, in this part of the world.

\section{REFERENCES:}

1. Scott-brown's Otolaryngology, 6th edition, Pediatric otolaryngology, $6 / 15 / 18$

2. Brown K, Brown OE. Congenital malformation of the nose. In: Cummings CW, ed. Otolaryngology-Head and Neck Surgery. 3rd ed. St. Louis: Mosby, 1998:92-103.

3. Kurul, OzcarG, Cacalir.C.European archives of Otorhinolaryngology 1995, 252(1)61-2.

4. Linsday B. A nose with supernumerary nostrils. Transactions of the Pathology Society of London 1906; 57:329.

5. Erich JB. Nasal duplication. Report of case of patient with two noses. Plast Reconstr Surg 1962;29:159-66.

6. Onizuka T, Tai Y. Supernumerary nostril. Case report. Plast Reconstr Surg 1972; 50:403-5.

7. Chen MT, Yeong EK. Supernumerary nostrils. Br J Plast Surg 1992; 45:557-8. 
8. Hallak A, Jamjoom H,Hosseinzadeh T. Supernumerary nostrils: A case report and review. Aesthetic Plast Surg 2001; 25:241-3.

9. Nakamura $K$, Onizuka T. A case of supernumerary nostril. Plast Reconstr Surg 1987;80:436-41.

10. G. CUERVO DE LA CALLE, E. VIVIENTE RODRÍGUEZ, A. CAPITÁN GUARNIZO,etal, Supernumery nostril, Acta otorrinolaringol Esp 2004, 55:93-96
Address for Correspondence:

Prof. Dr. N.Radhakrishna, Government ENT.Hospital,

Koti, Hyderabad

Andhra Pradesh.

\title{
A CASE STUDY OF PLUMMER-VINSON SYNDROME
}

\author{
Vikas Sinha, ${ }^{*}$ Bela Prajapati, ${ }^{* *}$ Ajay George, ** Devang Gupta.**
}

\begin{abstract}
The case series presents the pattem of association of different co-morbid conditions of Plummer Vinson's Syndrome. The commonest morbidity is web at post cricoid level. The symptoms of dysphagia are more common and there appears to be a female preponderance. The presenting age us usually Sth decade. Although association with post cricoid carcinoma has beet reported but only 10\% of cases in the present series had carcinoma at the time of presentation. The effect of iron and B-complex supplementation has been clinically appraised and good symptomatic relief has been seen. Maybe this measure can prevent the progression to malignancy. Bouginage was effective in relieving symptoms in all the cases it was tried
\end{abstract}

Keywords : Plummer Vinson Syndrome, Postcricoid web.

\section{INTRODUCTION}

Plummer-Vinson syndrome or Patterson-Kelly syndrome is characterized by dysphagia which is usually due to upper esophageal web, anemia, splenomegaly and other features like angular chelitis and glossitis. A prospective study was conducted in $\mathrm{BJ}$ medical college, Ahmedabad with an aim to find out the age and sex incidence of this syndrome. To evaluate the results of iron and B-complex supplementation with esophageal dilation and find out relationship with post-cricoid carcinoma, if any.

\section{MATERIALS AND METHODS}

25 confirmed cases of Plummer-Vinson syndrome were included in the study after taking detail history and detail examination, all cases were investigated for all routine blood parameters including blood indices and radiological investigation barium swallow and other indicated investigations. The patients are subsequently put on iron and B-complex therapy. Rigid endoscopy was done, webs and strictures were dilated and biopsy of suspicious lesions was taken. The patients were adequately followed up and any needed further management was instituted.

\section{OBERVATIONS}

Out of 25 cases of the present series, 22 patients i.e. $88 \%$ were females and the rest were males. The age distribution is as shown in table A. 12 patients were in the $5^{\text {th }}$ decade of life. Next highest was 7 cases in $4^{\text {th }}$ decade of life. The remaining cases were sparsely distributed over the other decades. The youngest was 20 year old and the oldest was 65 -year old. 2 patients had a past history of oesophagoscopy and dilatation, where as 2 patients had a history of surgery for acid peptic disease. The symptomatology is as shown in Table B. All cases had dysphagia other symptoms like soreness of mouth, easy fatigability, palpitation, parasthesia, giddiness, dysponea and malena were present in varying proportions.

Grade I dysphagia where in patient has only difficulty in swallowing solids was present in $52 \%$ cases. Grade II dysphagia where in patient can take only semisolids was present in $36 \%$ patients. Grade III dysphagia where in patient can take only liquids was present in $8 \%$ cases. Difficulty to swallow even saliva i.e. grade IV was present in $4 \%$ cases. Among clinical features signs of iron deficiency, anemia like bald tongue, pallor, koilonychia were present in all cases. Angular chelitis and glossitis was present in $80 \%$ and $60 \%$ cases respectively. Splenomegaly was found only in 4 cases.

All patients had hemoglobin less than $10 \mathrm{gm} \%$ and 8 cases were severely anemic with hemoglobin less than $5 \mathrm{gm} \%$. Blood indices like PCV, MCV, MCHC, serum iron and total iron binding capacity revealed microcytic hypochromic anemia with iron deficiency in all cases. Urine analysis was normal in all cases. Stool examination revealed occult blood in 2 cases. Gastric analysis reveled achlorohydria in 3 cases. Radiological investigation reveled post cricoid web in 4 cases, benign stricture in 1 case, malignant stricture in 2 cases \& surprising normal finding in 12cases. All cases in spite of barium swallow findings underwent rigid oesophagoscopy under general anesthesia which showed post cricoid web in 15 cases. These webs were commonly situated on lateral wall. Stricture was present in 4 cases. Exophytic growth was seen in 2 cases which proved to be malignancy on biopsyand histo-pathological examination during endoscopy full dilation with gum elastic bougies was carried out in 19 cases. All patients except those with malignant growth were started on full diet next day itself iron and vitamin supplements was instituted in all cases.

*Professor and Head, **Assistant Professors, Department of Otolaryngology and Head and Neck Surgery, B.J.Medical College, (Civil Hospital), Ahmedabad, (Gujarat) 